\title{
Predictive value of C-reactive protein and carotid intimal medial thickness in acute ischemic stroke
}

\author{
Mahmoud Elbelkimy, Naglaa ELkhayat, Ahmed ElSadek*, Alia Mansour and Mariam Aboutaleb
}

\begin{abstract}
Background: Elevated CRP and increased CCA-IMT are both associated with the occurrence of stroke. CRP and IMT are closely associated; the higher the CRP, the greater the carotid atherosclerosis as measured by carotid IMT.

Objectives: To study the relationship between elevated C-reactive protein as a blood biomarker and increased intimal media thickness of carotid artery, and its relation to infarct size and its impact on prognosis.

Materials and methods: This study is an analytical observational study, in which 73 patients who have recently suffered first-ever acute ischemic stroke in the anterior circulation within $72 \mathrm{~h}$ were recruited. Only 64 of them were able to continue the study with follow-up during the 1 month and 3 months durations. Magnetic resonance imaging for the brain was done and the infarct volume was measured. All patients had quantitative Serum CRP level within $72 \mathrm{~h}$ from stroke onset and carotid duplex with assessment of carotid intimal media thickness (IMT).

Results: The results showed there is a significant positive correlation between highly sensitive C-reactive protein (hs-CRP) and MRS after 1 month yet no significant correlation was found between hs-CRP and IMT.

Conclusion: Highly sensitive C-reactive protein (hs-CRP) could serve as prognostic blood biomarker in long-term follow-up of stroke patients. Non-significant correlation was found in our study between increased hs-CRP and increased intima-media thickness (CCA-IMT).
\end{abstract}

Keywords: C-reactive protein, Carotid intima-media thickness, Acute ischemic stroke

\section{Introduction}

Increased intima-media thickness is considered the earliest sign of carotid atherosclerosis. IMT is measured on the far wall of distal common carotid arteries (CCA). There is an association between brain infarction (BI) and common carotid arteries-intima media thickness (CCAIMT); this association was present in the main BI subtypes [1]. Major anterior circulation ischemic strokes, caused by occlusion of the distal internal carotid artery or proximal middle cerebral artery or both, accounts for about one-third of ischemic strokes with mostly poor outcomes. The pathophysiology of stroke is complex and involves excitotoxicity mechanisms, inflammatory pathways, oxidative damage, ionic imbalances, apoptosis, angiogenesis, and neuroprotection [2,3]. As a reflector of systemic atherosclerosis, increased carotid artery IMT

* Correspondence: ahmedelsadek_79@yahoo.com

Ainshams University, 19/1/42, Elrehab City, Cairo P.O. 11841, Egypt has been associated with a higher risk for stroke. Each 1 standard deviation (SD) change in IMT increased the incidence of future stroke by approximately $30 \%$, independent of traditional cardiovascular risk factors $[4,5]$. Elevated CRP and increased CCA-IMT are both associated with the occurrence of stroke. CRP and IMT are closely associated; the higher the CRP, the greater the carotid atherosclerosis as measured by carotid IMT [6]. $\mathrm{C}$-reactive protein is an acute-phase reactant with halflife 19-h, synthesized by liver within $6 \mathrm{~h}$ of an inflammatory stimulus, e.g., acute ischemic stroke, ischemic heart disease, and autoimmune disorders. It is also suggested that C-reactive protein is a marker of inflammatory process and has an important value in coronary artery disease and also important prognostic factor ischemic stroke patients [7]. The development of atherosclerosis is now considered to be due in part to an inflammatory response. Several investigators have examined a variety 
of circulating markers of inflammation as potential predictors of the presence of cardiovascular disease (CVD) and the risk of future CVD events. Of the variety of circulating markers $\mathrm{C}$-reactive protein has the most consistent relations to the risk of CVD events in a variety of clinical settings. High-sensitivity CRP predicts CVD risk in healthy men and women, in selected high-risk patients with traditional risk factors, and among patients with CVD. The ability of hs-CRP to predict CVD risk is independent of the effects of traditional risk factors. Earlier carotid atherosclerosis, without direct threat to the brain, has been linked to an elevated risk for stroke. The linkage is supported by an association between carotid and systemic atherosclerosis [8].

\section{Aim of the work}

To study the correlation between C-reactive protein as a blood biomarker and intimal media thickness of the carotid artery, and its relation to infarct size and its impact on prognosis.

\section{Materials and methods}

This study is an analytical observational study, in which 73 patients who have recently suffered acute ischemic within $72 \mathrm{~h}$, were recruited from Ain-Shams University Hospitals from October 2014 and May 2015. Only 64 of them were able to continue the study with follow-up during the 1 month and 3 months durations.

\section{Inclusion criteria and subject selection}

Stroke patients who were included in the study had the following criteria: first ischemic stroke, and admitted to the hospital within $72 \mathrm{~h}$ of onset of stroke of anterior circulation origin.

\section{Exclusion criteria}

Transient ischemic attack, recurrent stroke or second stroke, intracerebral hemorrhage, subarachnoid hemo rrhage, posterior circulation stroke, lack of baseline data, if they received intravenous or intra-arterial thrombolytic therapy; interventional treatment, ongoing acute coronary syndrome. Patients with clinical symptoms and signs of active infection including fever, cough, burning micturition, asymptomatic subjects with evidence of infection on investigations such as leukocytosis on peripheral smear, infiltrates on chest radiograph, patients with a history of prior inflammatory diseases, like rheumatoid arthritis and systemic lupus erythematosus (SLE), and those on steroids or immunomodulatory drugs were also excluded, evidence of cardioembolic stroke and patients refused to participate in the study protocol.

\section{Ethical consideration}

The study was approved by Ain-Shams University Ethical Committee. All patients or relatives are informed with written consent was taken about the study and its possible benefits.

- A total of 64 patients of acute ischemic stroke within $24 \mathrm{~h}$ from stroke onset were enrolled. All patients had a detailed neurologic examination and relevant investigation to determine the mechanism of stroke and also the risk factors. Patient's neurological status was assessed via National Institute of Health and Stroke Scale (NIHSS) which was done on admission and after 1 month and modified Rankin Scale (mRS) after 3 months. All patients had quantitative serum CRP level using a turbid metric assay, the samples were collected within $24 \mathrm{~h}$ from stroke onset and the cut points of low risk is $(<1.0 \mathrm{mg} / \mathrm{L})$, average risk $(1-3 \mathrm{mg} / \mathrm{L})$, and high risk ( $>3 \mathrm{mg} / \mathrm{L})$.

- Magnetic resonance imaging of the brain (MRI) was done for all patients. The infarct volume can be reliably approximated using the formula $A B C / 2$, where $\mathrm{A}, \mathrm{B}$, and $\mathrm{C}$ are the longest three orthogonal distances of the lesion as measured on the MR console [9]. According to infarction volume, small vessel disease was considered that of less than 508 $\mathrm{mm}^{3}$, while large vessel disease exceeds $508 \mathrm{~mm}^{3}$ [3]. Carotid duplex with assessment of carotid intimal media thickness which was measured at the distal part of CCA before carotid bulb manually (using General Electric Logic 5, USA machine with linear probe "5-13 M hertz") and it was considered abnormal when it exceeds $0.8 \mathrm{~mm}$.

\section{Statistical analysis}

The collected data of the present study was revised, coded, tabulated, and statistically analyzed using Statistical Package for Social Sciences (SPSSR); software program version 20.0. Data was presented and suitable analysis was done according to the type of data obtained for each parameter.

\section{Descriptive statistics}

Mean, standard deviation, and minimum and maximum of the range for numerical data.

\section{Analytical statistics}

Student's $t$ test was used to assess the statistical significance of the difference between the two study group means.

Correlation analysis using Pearson's method was done to assess the strength of association between two quantitative variables. The correlation coefficient denoted symbolically " $r_{\mathrm{s}}$ " defines the strength and direction of the 
Table 1 Age and gender of patients recruited in this study

\begin{tabular}{lll}
\hline Gender & Male N (\%) & $36(56.3 \%)$ \\
& Female N (\%) & $28(43.8 \%)$ \\
Age, mean \pm SD & $62.47 \pm 10.03$ & \\
\hline
\end{tabular}

linear relationship between two variables. The level of significance was considered significant at $P$ value of $\leq 0.05$, otherwise was non-significant at higher $P$ values. The $P$ value is a statistical measure for the probability that the results observed in a study could have occurred by chance. Chi-square test was used to examine the relationship between two qualitative variables.

\section{Results}

Analysis of the demographic data showed that this study included 36 males (56.3\%) and 28 females (43.8\%), and their mean age was $62.47 \pm 10.03$ ranging from 45 to 89 as shown in (Table 1).

Highly sensitive C-reactive protein (Hs-CRP) among patients showed mean value $0.99 \mathrm{mg} / \mathrm{dL} \pm 0.91$ ranging from $0.1 \mathrm{mg} / \mathrm{dL}$ to $3.8 \mathrm{mg} / \mathrm{dL}$.

Vascular risk factors (e.g., dyslipidemia, diabetes, hypertension, and ischemic heart disease) were assessed in our study as follows:

Low-density lipoprotein (LDL) showed mean value $117.45 \mathrm{mg} / \mathrm{dL} \pm 40.65$ ranging from $36 \mathrm{mg} / \mathrm{dL}$ to $257 \mathrm{mg} /$ dL. High-density lipoprotein (HDL) showed mean value $45.92 \mathrm{mg} / \mathrm{dL} \pm 12.68$ ranging from $27 \mathrm{mg} / \mathrm{dL}$ to $81 \mathrm{mg} / \mathrm{dL}$.

Glycated hemoglobin (HbA1c) showed a mean value $6.99 \% \pm 1.75$ ranging from 4.5 to $13.5 \%$.

Troponin showed with value $0.1 \mathrm{ng} / \mathrm{mL} \pm 0.1$ ranging from $0 \mathrm{ng} / \mathrm{mL}$ to $0.04 \mathrm{ng} / \mathrm{mL}$.

On the measurement of blood pressure, it was found that mean systolic blood pressure (SBP) on admission was $152.19 \mathrm{mmHg} \pm 24.33$ ranging from 100 to 220 $\mathrm{mmHg}$, mean diastolic blood pressure (DBP) was 89.69 $\mathrm{mmHg} \pm 9.59$ ranging from 60 to $110 \mathrm{mmHg}$ as shown in Tables 2 and 3.

In this study, we correlate hs-CRP values with values of LDL (as an indicator for dyslipidemia). It was found that $78 \%$ of patient with high level of LDL had high hs-

Table 2 Mean systolic and diastolic blood pressure on admission

\begin{tabular}{llll}
\hline & Mean & SD & Range \\
\hline $\begin{array}{l}\text { Systolic blood pressure } \\
\text { (SBP) on admission }\end{array}$ & 152.19 & 24.33 & $100-220$ \\
mmHg & & \\
$\begin{array}{l}\text { Diastolic blood pressure } \\
\text { (DBP) on admission }\end{array}$ & 89.69 & 9.59 & $60-110$ \\
mmHg & & & \\
\hline
\end{tabular}

Table 3 Mean value of common carotid artery intimal medial thickness

\begin{tabular}{lcl}
\hline & Mean & SD \\
\hline Carotid duplex IMT & 1.25 & 0.58
\end{tabular}

CRP value. While only $21 \%$ of people with high serum LDL had a normal value of hs-CRP.

Patients were assessed using NIH stroke scale on admission, after 1 month and by modified Rankin scale after 3 months, mean value of NIH stroke scale on admission was $6.48 \pm 2.97$ ranging from 1 to 16 , mean value of NIH stroke scale after 1 month was $4.5 \pm 2.48$ ranging from 0 to 9 , mean value of modified Rankin scale after 3 months was $2.13 \pm 1.09$ ranging from 0 to 4 .

- NIH on admission, after 1 month and MRS after 3 months (Table 4) (Fig. 1)

In this study, the mean value of common carotid artery intimal medial thickness was 1.25 as shown in Table 5

- Common carotid artery intimal medial thickness

- Large versus small vessel stroke according to TOAST criteria among patients:

According to TOAST classification, percentage of large vessel stroke was 21.9 and small vessel stroke was 78.1 as shown in Table 6

- Correlation between hs-CRP and IMT

There was non significant correlation between HsCRP and IMT as shown in Table 7

- Comparison between patients with large and small volumes regarding Hs-CRP value (Table 8) (Fig. 2)

Table 4 Mean value of $\mathrm{Hs}-\mathrm{CRP}, \mathrm{LDL}, \mathrm{HbA1c}, \mathrm{HDL}$, and troponin among patients

\begin{tabular}{llll}
\hline & Mean & SD & Range \\
\hline $\mathrm{Hs}-\mathrm{CRP}$ & .99 & .91 & $0.1-3.8$ \\
$\mathrm{mg} / \mathrm{dL}$ & & & $36-257$ \\
$\mathrm{LDL}$ & 117.45 & 40.65 & \\
$\mathrm{mg} / \mathrm{dL}$ & & & $4.5-13.5$ \\
$\mathrm{HbA1c} \%$ & 6.99 & 1.75 & $27-81$ \\
$\mathrm{HDL}$ & 45.92 & 12.68 & \\
$\mathrm{mg} / \mathrm{dL}$ & & & $0-0.04$ \\
$\begin{array}{l}\text { Troponin } \\
\mathrm{ng} / \mathrm{mL}\end{array}$ & .01 & .01 & \\
\hline
\end{tabular}




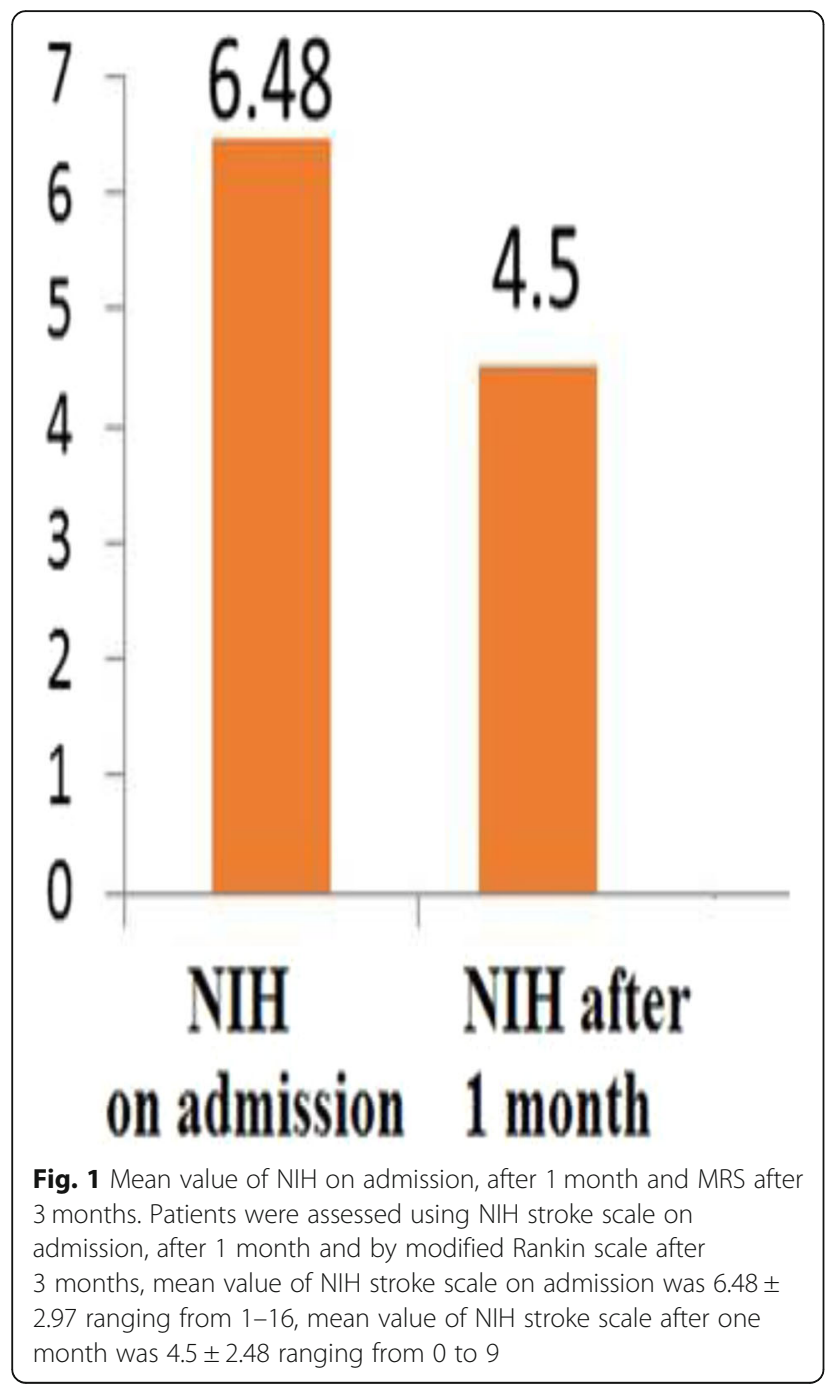

There was non significant difference between patients with large and small volumes regarding Hs-CRP value as shown in Table 8

- Correlation between the volume of infarction and the intimal medial thickness:

There was non significant difference between stroke volume and IMT on the symptomatic side and on the asymptomatic side as shown in Table 9

Table 5 Mean value of $\mathrm{NIH}$ on admission after 1 month and MRS after 3 months

\begin{tabular}{llll}
\hline & Mean & SD & Range \\
\hline NIH on admission & 6.48 & 2.97 & $1-16$ \\
NIH after 1 month & 4.50 & 2.48 & $0-9$ \\
MRS & 2.13 & 1.09 & $0-4$ \\
\hline
\end{tabular}

Table 6 Percentage of large versus small vessel stroke according to TOAST criteria among patients

\begin{tabular}{lll}
\hline & Number $(\mathrm{N})$ & Percentage (\%) \\
\hline Large vessel stroke & 14 & 21.9 \\
Small vessel stroke & 50 & 78.1 \\
\hline
\end{tabular}

- Correlations between Hs-CRP and NIH on admission, NIH after 1 month and MRS

There was significant correlation between Hs-CRP and MRS after 1 month yet non significant correlation with $\mathrm{NIH}$ on admission and after 1 month as shown in Table 10.

\section{Discussion}

This study is considered pilot study aimed to correlate between C-reactive protein as a blood biomarker and intimal media thickness of carotid artery, and its relation to infarct size and its impact on prognosis using clinical scales (NIHSS and MRS) which show significantly positive correlation between highly sensitive C-reactive protein with carotid intimal media thickness and also with MRS after 1 month. Elevated CRP and increased common carotid artery-intimal medial thickness (CIMT) are both associated with the occurrence of stroke. CRP and IMT are closely associated; the higher the CRP, the greater the carotid atherosclerosis as measured by carotid IMT [6]. Many studies demonstrated that high levels of inflammatory mediator such as plasma IL-6, TNF, IL-1, and CRP could predict stroke severity and poor long-term outcome have. CRP is one of the most extensively studied markers, which was associated with all stages of atherosclerosis, from the formation of the plaque to the occurrence and the progression of acute ischemic stroke [10].

In the current study, we correlate hs-CRP and CIMT which was non-significant may be due to high percentage of stroke patients with Small vessel occlusion subtype in comparison to other subtypes of stroke in our sample. This result is different from meta-analysis done by Baldassarre and his colleagues $[2,11]$, who studied in their meta-analysis the relationship between plasma levels of hs-CRP and C-IMT of 65 groups within 54 studies. A significant univariate correlation/association was found in 39 groups

Table 7 Correlation between hs-CRP and IMT

\begin{tabular}{lll}
\hline & & IMT \\
\hline Hs-CRP & $r_{\mathrm{s}}$ & 0.234 \\
& $P$ value & 0.063 non-significant (NS) \\
\hline
\end{tabular}


Table 8 Comparison between patients with large and small volumes regarding hs-CRP value

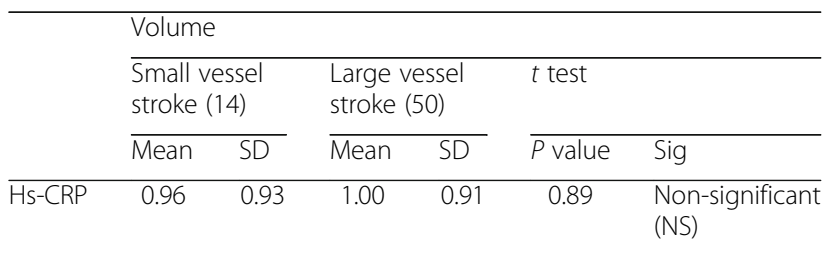

(60\%) within 29 studies. Whereas fewer than 4 (5\%) were expected by chance if there were no relationship between the two variables and assuming no publication bias.

Correlations between hs-CRP and NIH on admission, NIH after 1 month and MRS were done, it showed there was a positive significant correlation between Hs-CRP and MRS while no significant correlations were found as regards hs-CRP and NIH on admission. However, in a study done by Shoeab and his colleagues [9] where 50 patients with a first-ever acute stroke and they assessed stroke severity by the National Institute of Health Stroke Scale (NIHSS),



Table 9 Correlation between stroke volume and IMT on the symptomatic side and on the asymptomatic side

\begin{tabular}{lll}
\hline & & IMT \\
\hline MRI stroke volume & $r_{\mathrm{s}}$ & -0.11 \\
& $P$ value & 0.40 non-significant \\
& & $(\mathrm{NS})$ \\
\hline
\end{tabular}

Hs-CRP level assay and CT brain were done to all patients on admission. Further assessment was done 7 days later, and the outcome was evaluated by a modified Rankin Scale (mRS). Results revealed that serum Hs-CRP level on admission was predictive of stroke severity (positively correlated with NIHSS, as well as outcome positively correlated with mRS, which was consistent with the current study yet they had shorter follow-up and smaller sample size.

While comparing large vessel stroke with small vessel stroke, no significant correlation was found between high value of CRP and large vessel and small vessel disease stroke. This may be due to the small sample size of our study in comparison to other studies that show significant correlation between level of hs-CRP and type of stroke. In contrast to a study done by Terruzzi and his colleagues [12], where patients were included after a first-ever CT/MR documented cerebral infarction. Hs-CRP was measured from blood samples. The study included 648 stroke patients. CRP levels were mostly increased in large vessel stroke, followed by small vessel stroke. They had larger sample size than the current study which may account to the non-significant results.

In the current study results, there was non-significant correlation between IMT with MRI stroke volume. This could be explained by the fact that IMT assesses the common carotid artery which is considered a large artery, yet not enough information about the status of small vessels is indicated by carotid duplex IMT. The result was in favor with previous study done by Nagai and his colleagues [13] which did not find significant difference between CCA-IMT in large vessel disease (LVD) and small vessel disease (SVD).

However, one of the limitations of our study is the small sample size. So, this study can be considered as a pilot study.

Table 10 Correlation between hs-CRP and NIH on admission, $\mathrm{NIH}$ after 1 month and MRS

\begin{tabular}{|c|c|c|c|c|c|}
\hline & & $\begin{array}{l}\text { NIH on } \\
\text { admission }\end{array}$ & $\begin{array}{l}\text { NIH after } 1 \\
\text { month }\end{array}$ & MRS & $\begin{array}{l}\mathrm{NIH} \text { percent of } \\
\text { change }\end{array}$ \\
\hline \multirow{2}{*}{$\begin{array}{l}\text { Hs- } \\
\text { CRP }\end{array}$} & $r_{\mathrm{s}}$ & 0.23 & 0.21 & 0.28 & -0.179 \\
\hline & $\begin{array}{l}P \\
\text { value }\end{array}$ & $0.06 \mathrm{NS}$ & 0.09 NS & $\begin{array}{l}0.02 \\
\text { Significant } \\
(\mathrm{S})\end{array}$ & 0.156 NS \\
\hline
\end{tabular}




\section{Conclusion}

At the end of the study, it was concluded that highly sensitive C-reactive protein (hs-CRP) could serve as prognostic blood biomarker in long-term follow-up of stroke patients. Non-significant correlation was found in our study between increased hs-CRP and increased intima-media thickness (CCA-IMT).

\section{Abbreviations}

BI: Brain infarction; CCA: Common carotid arteries; CCA-IMT: Common carotid arteries-intima-media thickness; CVD: Cardiovascular disease; DBP: Diastolic blood pressure; HbA1c: Glycated hemoglobin; HDL: High-density lipoprotein; Hs-CRP: Highly sensitive C-reactive protein; IMT: Intima media thickness; LDL: Low-density lipoprotein; mRS: Magnetic resonance imaging (MRI), modified Rankin Scale; N: Number; NIHSS: National Institute of Health and Stroke Scale; NS: Non-significant; S: Significant; SBP: Systolic blood pressure; SD: Standard deviation; SLE: Systemic lupus erythematosus; SPSSR: Statistical Package for Social Sciences

\section{Acknowledgements}

Not applicable.

\section{Authors' contributions}

ME and AE conceived of the study and participated in its design and coordination and helped to draft the manuscript (FG). AM and NE participated in the sequence alignment (MT). MA participated in the design of the study and performed the statistical analysis (ES). All authors read and approved the final manuscript.

\section{Funding}

Not applicable.

\section{Availability of data and materials}

Dataset is available as a master sheet in Excel format and publicly available in Neurology Department, Ain-Shams University through communicating corresponding authors.

\section{Ethics approval and consent to participate}

The study was approved by Ain-Shams University Ethical Committee in October 2014. Written informed consent was obtained from the patients participating in the study.

\section{Consent for publication}

Not applicable.

\section{Competing interests}

The authors declare that they have no competing interests.

Received: 23 February 2018 Accepted: 3 September 2019

Published online: 28 November 2019

\section{References}

1. Bathala L, Mehndiratta MM, Sharma VK. Cerebrovascular ultrasonography: technique and common pitfalls. Ann Indian Acad Neurol. 2013;16(1):121-7.

2. Deb P, Sharma S, Hassan KM. Pathophysiologic mechanisms of acute ischemic stroke: an overview with emphasis on therapeutic significance beyond thrombolysis. Pathophysiology. 2010;17(3):197-218.

3. Hakimelahi R, Vachha BA, Copen WA, et al. Time and diffusion lesion size in major anterior circulation ischemic strokes. Stroke. 2014. https://doi.org/10. 1161/STROKEAHA.114.005644

4. Martinic-Popovic I, Simundic AM, Dukic $L$, et al. The association of inflammatory markers with cerebral vasoreactivity and carotid atherosclerosis in transient ischaemic attack. Clin Biochem. 2014:47(16-17):182-6.

5. Wang TJ, Nam BH, Wilson PW, et al. Association of C-reactive protein with carotid atherosclerosis in men and women: the Framingham Heart Study. Arterioscler Thromb Vasc Biol. 2002;22:1662-7.

6. Ock SY, Cho Kl, Kim HJ, et al. The impacts of C-reactive protein and atrial fibrillation on carotid atherosclerosis and ischemic stroke in patients with suspected ischemic cerebrovascular disease: a single-center retrospective observational cohort study. Korean Circ J. 2013:43(12):796-803.

7. Sadreddini SA, Abolfathi AA, Khandagi R. C-reactive protein, fibrinogen, lipoprotein (a), and lipid profile levels and platelet counts in ischemic stroke patients. Neurosciences (Riyadh). 2007;12(3):202-6.

8. Salisbury D, Bronas U. Inflammation and immune system contribution to the etiology of atherosclerosis: mechanisms and methods of assessment. Nurs Res. 2014;63(5):375-85.

9. Shoeab MA, Shehata MA, Taema KM, Hammouda MA. CRP in cerebrovascular stroke: prognostic implications. Egypt J Crit Care Med. 2014;2(1):43-52.

10. Zeng $L, H e X$, Liu J, et al. Differences of circulating inflammatory markers between large- and small vessel disease in patients with acute ischemic stroke. Int J Med Sci. 2013;10(10):1399-405.

11. Baldassarre D, De Jong A, Amato $M$, et al. Carotid intima-media thickness and markers of inflammation, endothelial damage and hemostasis. Ann Med. 2008;40:21-44

12. Terruzzi $A$, Valente $L$, Mariani $R$, et al. C-reactive protein and aetiological subtypes of cerebral infarction. Neurol Sci. 2008;29:245-9.

13. Nagai $Y$, Kitagawa $\mathrm{K}$, Yamagami $\mathrm{H}$, et al. Carotid artery intima-media thickness and plaque score for the risk assessment of stroke subtypes. Ultrasound Med Biol. 2002;28:1239-43.

\section{Publisher's Note}

Springer Nature remains neutral with regard to jurisdictional claims in published maps and institutional affiliations.

\section{Submit your manuscript to a SpringerOpen ${ }^{\circ}$ journal and benefit from:}

- Convenient online submission

- Rigorous peer review

- Open access: articles freely available online

- High visibility within the field

- Retaining the copyright to your article

Submit your next manuscript at $\boldsymbol{\nabla}$ springeropen.com 